\title{
OBSERVAÇÃO SISTEMÃTICA DOS PROCEDIMENTOS DA EQUIPE DE ENFERMAGEM NA COLETA DE URINA PARA CULTURA
}

\author{
Sofia M.T.B. Valente*
}

\author{
NOTA PRÉVIA
}

VALENTE, S.M.T.B. Observação sistemática dos procedimentos da equipe de enfermagem na coleta de urina para cultura. Nota prévia. Rev. Esc. Enf. USP, São Paulo, 14 (3): 337, 1980.

Sabemos que há grande diversidade nos procedimentos utilizados pela equipe de enfermagem quanto à coleta de urina para cultura, nas técnicas de jato-médio e cateterismo vesical. Como consequiência da não observação de princípios básioos nessas técnicas, o paciente pode sofrer inumeráveis danos.

Cientes da necessidade de estudar tais procedimentos, nos propomos a fazer um levantamento do uso de princípios básicos em hospitais e laboratórios de análises clínicas da cidade de São Paulo.

A coleta de dados será feita por meio de observaçâo sistematizada com instrumento especialmente elaborado. Este instrumento apresenta condiçōes de registro de dados para identificação e de cinco variáveis: preparo do ambiente e do material; preparo do paciente; procedimentos durante a coleta de urina e cuidados com o paciente; cuidados com a amostra e com o material utilizado.

Cada variável possui indicadores a ela ligados e cada indicador recebe cinoo categorias. Essas categorias foram definidas em estudo prévio. Os pesos dados à cada categoria nos levarão a um resultado qualitativo dos procedimentos como um todo, em suas variáveis e indicadores.

Acreditamos que o presente estudo irá mostrar a qualidade dos procedimentos utilizados atualmente e estes resultados poderão servir de guia para uma modificação no ensino de tais procedimentos.

A presente pesquisa encontra-se na fase de pré-teste do instrumento para coleta de dados.

VALENTE, S.M.T.B. Systematic observation of nursing team's procedures in urine collect to culture. Previous note. Rev. Esc. Enf. USP, São Paulo, 14 (3): 337, 1980.

The objective of this paper is to study the quality of procedures utilized by nursing team in urine collect to culture in hospitals and laboratories of Sío Paulo City. 